Please do not remove this page

RMIT

UNIVERSITY

\title{
'These are issues that should not be raised in black and white': the culture of progress reporting and the doctorate
}

Mewburn, Inger; Tokareva, Ekaterina; Cuthbert, Denise; Sinclair, Jennifer; Barnacle, Robyn

https://researchrepository.rmit.edu.au/esploro/outputs/9921859709401341/filesAndLinks?institution=61RMIT_INST\&index=null

Mewburn, I., Tokareva, E., Cuthbert, D., Sinclair, J., \& Barnacle, R. (2014). "These are issues that should not be raised in black and white": the culture of progress reporting and the doctorate. Higher Education Research and Development, 33(3), 510-522. https://doi.org/10.1080/07294360.2013.841649

Document Version: Accepted Manuscript

Published Version: https://doi.org/10.1080/07294360.2013.841649

Repository homepage: https://researchrepository.rmit.edu.au

(c) 2013 HERDSA

Downloaded On 2023/04/27 01:26:53 +1000

Please do not remove this page 
Thank you for downloading this document from the RMIT Research Repository.

The RMIT Research Repository is an open access database showcasing the research outputs of RMIT University researchers.

RMIT Research Repository: http://researchbank.rmit.edu.au/

\section{Citation:}

Mewburn, I, Tokareva, E, Cuthbert, D, Sinclair, J and Barnacle, R 2014, "These are issues that should not be raised in black and white': the culture of progress reporting and the doctorate', Higher Education Research and Development, vol. 33, no. 3, pp. 510-522.

See this record in the RMIT Research Repository at:

https://researchbank.rmit.edu.au/view/rmit:23080

Version: Accepted Manuscript

Copyright Statement: (c) 2013 HERDSA

Link to Published Version:

http://dx.doi.org/10.1080/07294360.2013.841649 
'These are issues that shouldn't be raised in black and white': the culture of progress reporting and the doctorate

Inger Mewburn, RMIT University

Ekaterina Tokareva, RMIT University

Denise Cuthbert, RMIT University

Jennifer Sinclair, RMIT University

Robyn Barnacle, RMIT University

Corresponding author:

Robyn Barnacle, School of Graduate Research, RMIT University, PO Box 2476V, Melbourne Australia 3001.

robyn.barnacle@rmit.edu.au 


\title{
'These are issues that shouldn't be raised in black and white': the culture of progress reporting and the doctorate
}

\begin{abstract}
This paper reports findings from Australian research into student, academic and administrative staff understandings of the role and efficacy of periodic progress reports designed to monitor the progress of higher degree by research candidates. Major findings are that confusion as to the purpose and ultimate audience of these reports is linked to less than effective reporting by all parties; countersigning and report dependency requirements inhibit the frank reporting of progress, and 'social learning' impacts on the way candidates and sometime supervisors approach reporting obligations, running counter to institutional imperatives. We conclude that no ready or transparent nexus between the progress report and progress may be assumed. Fundamentally, this calls into question the usefulness of this process as currently implemented. Arising from this is the recommendation that progress reporting be linked to substantive reviews of progress and embedded in the pedagogy and curriculum of higher degree by research programs.
\end{abstract}

Keywords: audit cultures; Australian universities; PhD candidates; progress reporting; research supervision

\section{Introduction}

This paper reports on findings from a study undertaken at a large Australian middle-band university into student and staff understandings of the role and efficacy of periodic progress reports during higher degree candidature. Progress reporting, where students and supervisors report, retrospectively on work done over the last semester or year, is widespread in Australia, due in part to government legislation on international student visas. Data from the European Universities Association indicates that $87 \%$ of member universities rely on periodic progress reporting as their key management tool for doctoral progress so the findings in this paper have international implications (EUA, 2010). Progress reporting is designed to monitor and provide feedback to higher degree by research candidates on their progress.

Administrative paperwork could be called a 'blind spot' in the literature on research education. There is a significant body of research regarding the conduct of the supervisor/student relationship more broadly (Lee and Williams 1999; Lee, Johnson and Green 2000; Kelly 2009; Kiley and Wisker 2009; Cotterall 2011, among many others). Although some scholars have turned their attention on institutional practices around the administration of $\mathrm{PhD}$ assessment (Tinkler and Jackson, 2010; Holbrook et al, 2004), and others have looked closely at how supervisors give formative feedback to students (Cumming, 2009; Petersen 2007; Martinsuo \& Turkulainen, 2011) the rest of the paperwork which has started to pervade the administration of doctorates has been overlooked. A notable exception is research by co-author Cuthbert and Spencer (2001) (see also Cuthbert, 2004), who observed the paradoxical situation in faculty offices of 'filing cabinets bulging' with satisfactory progress reports while the performance of the cohort with respect to completion and attrition indicated the existence of problems which were not being reported on.

Progress reporting is an instrument common to the 'audit cultures' that have sprung up within universities within the last 20 or so years, in response to neo-liberal agendas of various national governments (Strathern, 2000). Under the influence of pervasive 'knowledge economy' discourses, many governments align the production of research with the promise of future knowledge-driven economic growth (Australian Business Foundation 1997; Organisation for Economic Co-operation and Development 1996, United Kingdom Department of Trade and Industry 1998). In pursuit of this promise, governments around the world are looking for ways to increase both the volume and the efficiency of research training (see for example Department of Education, Training and Youth Affairs 2001, UNESCO, 2004). Universities became participants in intensified competition for research funding and ranking at home and in international market. In the UK Research Assessment Exercise process has been first introduced in 1986 which established the practice of selective allocation of funds to universities (Lucas 2006, p.22). 
National imperatives to produce more research and more researchers have transformed longstanding problems and inefficiencies within research cultures - such as high attrition from doctoral programs - from discrete (even hidden) institutional knowledge into matters of national public concern (Halse \& Mowbray, 2011, Marginson and Considine, 2000; Kehm and Teichler, 2007). The Australian experience of government intervention in systems of research training has corollaries in the UK, New Zealand and many other national higher education systems during the last decade. Commenting on this phenomenon, Strathern (2000) notes that the academy has responded to external pressures for accountability by the development of a ubiquitous 'audit culture'.

Australia is well advanced along the path of regulation and auditing of the research training sector, with performance-based funding measures in place since the Commonwealth government introduced the Research Training Scheme (RTS) in 2001. The RTS reduced the funded period for the doctorate from 5 to 4 years and introduced an efficiency measure, allocating funding based on a completions-driven formula. Long completion times and high attrition rates, which, to some extent, were taken for granted within the academy as part of the tradition of doctoral study (Becher and Trowler 2001; Lovitts 2001; Golde 2005), are now exposed to scrutiny and, through this visibility, rendered no longer acceptable. Further, under the requirements of the RTS, Australian higher education providers are financially incentivised to avoid 'non-productive separations' (noncompletions) or carrying over-time students; both cohorts now represent a measurable (as distinct from the formerly invisible) financial drain on institutions and the public purse.

The RTS has compelled universities to review and enhance systems and processes to 'manage' research candidature. For example, the move across the Australian sector to supervisor training, development and accreditation is an RTS-driven initiative, as are systems for managing and reporting on candidacy as it proceeds. Now, a decade after this performance-based funding measure was introduced in 2001 and on the eve of a wholesale review of the RTS in 2012 (Department of Innovation, Industry, Science and Research 2011), is a timely moment to assess the effectiveness of some of these systems.

\section{The Progress Report}

Australian higher degree by research candidates - despite some moves to introduce more coursework - remain overwhelmingly focused on the production and assessment of a single piece of work, the thesis or the project/exegesis. While across the Australian sector, substantive milestone events such as Confirmation of Candidature and Completions Seminars are increasingly shaping candidature, the progress report, either annual or bi-annual, remains a standard feature of candidature management in many universities. The progress report usually requires research candidate and supervisor to offer an account of their actions and the state of the research, including the thesis itself, to the university. The candidate and supervisor each required to sign off on the account given by the other, is a feature of the Australian progress reporting protocol. The report is meant to act as part of the apparatus of formative assessment, which, as Crossouard (2008) points out is integral to the formation of academic identities and therefore is never merely 'paperwork'. Part of this power relation is played out in the practice of countersigning. Since the progress report is, for many institutions, the only official interim documentation in $\mathrm{PhD}$ candidature management, the report is a heavily loaded institutional document. Progress reports often play an important role in decisions to extend or terminate candidature and in the management of student complaints. Cuthbert and Spencer (2001) examined progress reports from students located in a large Australian faculty of humanities and social sciences who withdrew from candidature without completing their research. Using discourse analysis, they sought to measure the degree to which problems, which might have lead to withdrawal or non-completion, were flagged in the available document trail. They found that all too often problems were not identified in progress reports, concluding that: 'telling the truth is hard and the longer the truth goes untold the harder it becomes to "come clean"' (Cuthbert and Spencer 2001, p.4). Theoretically, the progress report exists to help managers 'see' inside the supervisor/student relationship and assess the risk of a candidate failing to complete or 
falling behind in the tight 4 year schedule to completion. There is a paucity of literature on this kind of managerial practice as it applies to higher degrees by research. This research gap is especially surprising given the intensity of government scrutiny on research education.

This article does not decry the existence of audit cultures in postgraduate research, although we do have concerns about the human cost of such practices, particularly given, as Sparkes (2007) and Thornton (2009) address, the connection between neo-liberal ideologies and the introduction of performance measures in research and the associated apparatus for measuring performance. Instead we seek to, as Gill (2009) suggests, turn a lens upon our own, institutional, labour processes, organisational governance and conditions of production. To this end we offer a critical examination of the gaps between auditors' aspirations and student and staff practices.

\section{Existing research on progress reporting and auditing}

According to Baird, the progress report is but one element of a 'congested' and complex network of accountability relationships in higher degree by research education (Baird 2010, 130). Accountability regimes tend to grow organically without due regard for possible displacement effects (2010, 132), or situations where intermediaries can come to be seen to be demanding accountability for their own purposes, rather on behalf of others (for instance, the university acting on behalf of the Commonwealth government or other funding agencies). Demands for transparency and openness in congested accountability landscapes can have the perverse effect of decreasing trust. Baird's insightful analysis helps us to see that accountability is not evenly distributed in the progress reporting system. By participating in the progress report the student becomes accountable to the supervisor, the school and the university. The university central administration becomes a proxy auditing body for Commonwealth government and, sometimes, foreign governments or other funding agencies, which provide funds to support $\mathrm{PhD}$ research. Supervisors, by providing commentary and feedback, make themselves accountable to the university administration in terms of quality and compliance. However, the supervisor's accountability to the student may be complicated by disciplinary mores and practices; concerns for the student's well-being and the relationship between them; and, on some occasions, seeking to conceal their own practices of less than attentive supervision.

\section{About the research}

\section{Institutional context of the research}

This study was conducted in a large Australian, middle-band, metropolitan, university. With the establishment of a research graduate school in 2010 a commitment was made to introduce a new online system. Preliminary analysis of the old paper-based progress reporting system revealed some disturbing anomalies. Significant numbers of candidates had never had an unsatisfactory progress report, despite being past their mandated submission date set by the RTS. The disparity between institutional notions of progress and the academic reporting of progress, as shown here, helped us formulate our questions, specifically: why does the present system work so badly as a mechanism for reporting and improving progress? How is it understood and used by key stakeholders: students and supervisors? And, how can it be improved, or reconceived?

\section{Data collection and method}

The first part of the research entailed a process audit; the findings of this part of the research are largely institution-specific and are not reported on here. The second part of the research comprised interviews with stakeholders, for which approval from the university's ethics committee was obtained. Focus groups were intended to be the primary research method because they provide participants with the opportunity to share ideas, beliefs and attitudes with people of a similar 
background (Morgan 1997). However, due to logistical constraints, all the supervisors and some of the student participants were interviewed separately.

Since it was preferable for participants to have some experience of the progress reporting system, only students at least two years into their candidature were selected from those who responded to our call for participants. In all, twenty students took part in the study; twelve in humanities, business or design disciplines and eight in the laboratory-based sciences/technologies or nursing. Fifteen students took part in the three focus groups and five students were interviewed separately. Sixteen supervisors took part in the interviews; one supervisor subsequently withdrew consent, which left us with a sample size of fifteen.

Each focus group and interview proceeded with a set of general questions about the participants' understanding of and approaches to the progress report process geared to their situation, whether as students or supervisors. The questions were designed to elicit narratives and reflection from the participants and draw out the individual experiences of progress reporting. All interviews were audio-taped and transcribed for later analysis. Analysis was based on techniques derived from grounded theory (Strauss and Corbin, 1998). Interviews were transcribed and subjected to a theme analysis by both researchers and an additional coder where possible. Pseudonyms are used in the quotations that appear below.

\section{Findings and analysis}

\section{Students' perspective: confusion over function of progress report.}

On the face of it, the purpose of the progress report seems clear: to measure and evaluate progress towards the completion of a research degree and to keep a record of issues which can affect candidate's progress. Yet our data indicates that research participants held surprisingly diverse ideas about the purpose of the progress report, some of which operated in direct contradiction to institutional imperatives.

Candidates spoke about the report in a variety of ways, for example: an empty 'rubber stamping' exercise; a 'spin job' providing a sanitised account of the research; an 'impression management device' to present themselves in a favourable light; a way of viewing a frozen moment in research time; a benchmarking opportunity against a backdrop of fuzzy expectations; a way to request resources and complain about infrastructure; an opportunity to reflect on learning; a chance to clarify supervisor expectations; or, a battleground in which the student struggled to be heard. Amidst this variety of understandings and responses to the progress report and its role in their research, it is notable that no participants spoke of the progress report neutrally; it was not described by participants as a chance simply to report what had happened in their research and candidature. Candidates told us that the progress report did not provide them with a way of planning research in advance and no candidate expressed the desire or willingness to comment on supervisor performance in writing. In fact, candidates consistently told us that the progress report was not a way they would choose to solve 'people problems' - of which candidature seemed to be full.

Although the issues noted above give the impression that the progress reporting process was perceived by students as a negative or pointless process, this was not consistently the case. Candidates could hold complex - and sometimes seemingly contradictory - conceptions of what the progress reporting process is for and what it does. The progress report seemed to be figured as a slightly pointless, but benign presence in trouble-free candidatures, as comments from Nigel, a student in computer science, suggest:

[M]y relationship with my supervisor is quite loose, in that he gives me room to explore where I want. So in reality the progress report form, as far as we are going, is just a rubber-stamp... I think in reality the current progress report is good in that it forces the conversation... 
This kind of 'rubber stamp' conversation can be a way for student and supervisor to reach a shared position on what is worth pursuing. The negotiation, however, is not always so equitable, as Steve, a $\mathrm{PhD}$ candidate in design told us:

Well [it's] not exactly negotiation. Negotiation is like a trades deal...What he said is I should focus on what I have done so far and what I will be doing in the near future rather than going off on tangents or coming back to stuff that we have already said is not going to be done.

In Steve's comment there is a sense that the student is being reined in and kept on the path by the progress report conversation, but most students reported that the process did not provide a good framework for forward planning. Some students reported anxieties about how much progress was 'enough', especially early in candidature, as Ylva, a $\mathrm{PhD}$ candidate in business commented:

[Y] ou are immersed in this thing called [a] PhD, wondering what it is that you are doing and then ...you have to report your progress... initially I found it quite shocking because ... I think, "Oh, my God, I have done nothing.” And then I go, “Actually, you know, idiot, I have done heaps.” It's just that it's not necessarily - when you are doing it, you are not quantifying it or even qualifying it.

The planning paraphernalia which seemed to occupy many of the report forms we studied seeks to impose a linear understanding of research, which did not correspond to the lived experience of the research process, which required tangents and doubling back, for instance, to the literature. As Bruce, a candidate from business explains:

Every time one of the Gantt charts is assembled from the present off to the completion date, it's the bit that changes radically because the project is still moving around. So I've pretty much given up on directly following what any different previous Gantt chart suggests.

Bruce added that the Gantt charts became, instead, a way to measure the distance he has travelled from 'what I thought the project was going to be' as distinct from charting his progress against earlier plans. Even in the sciences, where we might assume there is a more staged approach to the research process, the linear model of progress seemed inadequate. Progress reports seemed to be a good way to gather material for the next progress report. Bruce claimed that the inaccurate projections of the future which the report demanded became a useful 'history of the past' which he used to make accounts of his progress:

[The progress report] crystallises ... what I think I'm doing my thesis on and how I think I'm doing it at that moment and then that inevitably changes, but then there's a folder on my computer that has a record of every three or six months where I've, sort of, frozen it and said “This is what I think I'm doing."

The progress reporting process assumes that there will be a ready nexus between the reporting of progress and progress itself, which is not borne out in our findings. In fact, it is the very ineffectiveness of the progress tool, the inability to use it to plan out research in advance, which was claimed by some students to be its strength because it provided an illusion of transparency without 'real teeth'.

\section{Supervisors’ perspectives}

Responses from supervisors on the purpose of progress reports provided an interesting counterpoint to candidate views. In many ways they aligned. For example, the most common ways the progress reports were talked about by supervisors were: a means of summarising what has occurred in supervisory meetings; an opportunity for the supervisor formally to articulate candidate's progress; an opportunity for a conversation between supervisor/candidate jointly to agree on progress or an administrative, compliance requirement that fails to capture the true nature of the candidate's progress (or lack of it). It is notable that most supervisors were less sensitive to the use of a progress report as an 'impression management device'; on the whole supervisors seemed to view the progress report as a banal administrative document, albeit one which they did not think they should 
use for more 'sensitive' issues. For example, fairly consistently, supervisors indicated that the progress report was not an effective means to capture/surface/signal concerns about progress.

These responses revealed that, like candidates, supervisors did not hold progress reviews in high regard as a planning tool; apart from the formal opportunity it provided to conduct periodic 'housekeeping'. Like the students, some supervisors expressed complex and even contradictory views of the progress report. In addition to the understandings listed above, some supervisors told us that the progress report was a three way conversation between student, supervisor and university to ensure good outcome for all; a means of disciplining the student (i.e. noting satisfactory rather than excellent progress); a 'crunch' moment for borderline students that might lead to withdrawal from candidature or changing supervisor; a means of triggering interventions from others on nonacademic issues; a means for either student or supervisor to communicate confidential information about the candidature that may need addressing; and a way to record serious supervisory misconduct. Some of these clearly contradict the findings reported above.

\section{Saying the unsayable? Inhibitions to frank reporting}

The findings above alert us to the fact that progress reports rarely reliably perform the task they are designed for: a straightforward reporting mechanism to describe what has happened during the research candidature. From the point of view of research managers, one of the weaknesses of the progress report system is a lack of truthful reporting (Cuthbert and Spencer 2001; Cuthbert 2004). Our data reveals the complexities around this phenomenon and caused us to question whether we would ever be able to design a system where the 'unspeakable' could be spoken. We found ample evidence of supervisor reluctance to take responsibility for reporting unsatisfactory progress in black and white which is the first step in initiating an 'at-risk' candidature classification. The participant responses highlighted the complex nature of student-supervisor relationships and, in particular, the difficulty some supervisors experience in managing students' emotional state throughout the degree. Many supervisors highlighted the difficulty they experienced being completely honest and reporting unsatisfactory progress. The progress report was too much of a 'high stakes' document to be of much use helping students through problems they were experiencing - many supervisors preferred to adopt a 'wait and see' approach and work to fix problems in other ways (with extra assistance for example, or by securing the student some leave from candidature and 'stopping the clock'). Laura, a supervisor in Science, summed up this dilemma when she outlined the unsuitability of the progress report for reporting grave candidature issues:

If the whole relationship broke down, if it became really bad and [the candidate] wasn't progressing and there was serious issues about ... completion, there might be some forum for discussing that but it certainly wouldn't be the progress report.

We found, without exception, that students refused to comment on their supervisors' performance and many participants, including the supervisors themselves, were reluctant to put sensitive information on a progress report.

\section{Reporting to whom?}

In many cases the students and supervisors in this study made a best guess at the 'audience' to whom the report is directed and responded accordingly. In some cases the student and supervisor participants presumed there was effectively no audience - that the report would merely be filed away for safe keeping. In other cases the imagined audience was an 'absent authority figure': someone in a position of authority who may have the power to intervene in the candidature for good or ill. This second imagined audience was regarded with various degrees of anxiety. The data reveal that both students and supervisors worked to create a specific version of the 'PhD researcher' for consumption by the absent authority figure. This might consist of making a more presentable account of the research and researcher which elided the more 'unpalatable' aspects of what had 
happened; or, it might comprise a 'warts and all' account as a pre-emptive move in the case of candidatures which may be failing.

\section{Social learning}

Our conversations with the students and the supervisors alerted us that learning how to do progress reports was, to a significant degree, a social process in which the learning was situated in a complex of networks which might extend beyond the institution itself (Lave and Wenger 1991). Some students reported difficulties filling out their first progress reports, at least in the early stages of their candidature. The supervisor was a very important figure in the students coming to know about administration and how the taken for granted institutional ways of dealing with it operate. The supervisor was often figured simultaneously as the 'back channel' and recording device; and the one actor who 'knows' what is going on and has the responsibility and power to act on this knowledge. Ana sums up this attitude well when she said:

[S]supervisors' should know about your life and I told them so I guess my belief was that your supervisor has some responsibility, if you tell them about your issues, to do something about it.

As we talked to candidates we found there was also a significant element of informal social learning occurring which shaped their attitudes to progress reporting. Students learned from other students and supervisors not only what was acceptable to put in reports, but what should be omitted.

We found that the way the progress report figured in the culture of candidature management affected how students learned to approach it, that is, whether they thought it was important or not to the business of doing research. Gerald, a social science $\mathrm{PhD}$ candidate, related a story which exemplified this social learning process. He reported that he 'learned quite quickly' that it was a 'rubber-stamping exercise' after the first time he did a report which offered a too complete account of what had happened in the process of doing the research:

I used the [first] report to describe those problems in case we needed to do something about those problems later in the process. But [my supervisor]) said “No. It’s not appropriate.” So I pulled them out.

Gerald's story is an interesting example of how, initially at least, a student may approach the progress report according to the central administration conception of it (as a record of evidence), but learns from the supervisor or others that this is not always how 'things are done' in practice and adjusts the report accordingly.

We further found that such stories have a way of circulating and colouring the perception of other candidates. When asked why she did not write down her troubles with her initial supervisor, Ylva, a business doctoral candidate explained:

I didn't really - did I want it in a report? I didn't think that anyone could do anything about it. So what was the point of putting something out there if nothing was going to be done about it?

When pressed to explain where she had formed this impression, Ylva admitted: 'I guess you hear it's that urban myth stories about other people's horrible experiences.'

We observed in the focus group interaction that the fears these stories provoked were highly contagious; especially stories about unspecified 'others' viewing and using reports for different purposes. Many candidates carried their own histories of institutional knowledge and behaviours with them. As Ada, an international communication candidate, remarked:

I did come with a lot of expectations because I thought that this institute would be much better from what I am coming from, but it wasn't any different, it was the same bureaucracy, the same power structures, everything was so similar. It was like "Wow! What?" You know, because [...] we come from the third world, we have [...] higher expectations than anybody else. 
Our research further revealed that this informal social learning process was not confined within the institution. Students inhabit a larger landscape and learn from the experiences of other people in similar situations to themselves, regardless of where they are located. Tony, an international $\mathrm{PhD}$ candidate in science, told us of the extended network of friends from his home country, all of whom were studying for their $\mathrm{PhD}$ at other institutions. It was this extra-institutional social network that taught Tony about the meaning and importance of progress reporting:

I got an e-mail - everyone got an e-mail. [I have] friends who are living here and I asked them, "What is the ... six-month report?" The notion was, like, "This is just a formality. That's it... It has no impact. I mean, it won't do anything with your progress ...you are not getting scholarship from [this institution]”.

While most students reported that the progress report was inadequate for solving 'people problems', students who had experienced problems in their candidature realised that the progress report itself could play a role in grievance procedures. However, most students, and the majority of supervisors, seemed to think that official channels, like the progress report, would simply escalate problems which instead called for local and sensitive solutions. As Nigel, a $\mathrm{PhD}$ candidate in computer science revealed: 'there are issues that shouldn't be raised in black and white; they should be raised by some other method'.

Irrespective of discipline or mode of research, research candidates in this study were highly sensitised to power relationships between students and supervisors, which many described as insurmountable. As Ana, completing a Communication doctorate, remarked:

[There's] tension and the bureaucracy, these things will not be able to be addressed in this system. They won't be. If you put another form and if you put another way, people will always be uncomfortable.

Without exception, candidates reported reluctance to comment on supervisor performance in writing. When relationships with supervisors were good, progress reviews were seen as a routine activity. Those who had trouble reported the progress report as a particularly uncomfortable process which provoked further tension. This tension arose, as several candidates reported, because supervisors were positioned as 'power brokers' both within and outside of the institution itself. As Bert, a PhD candidate in business explains:

After you graduate, you don't really want to try and start an academic career if there has been a relationship that's soured between you and one of the senior academics in that field, so there's a lot of power in the hands of the $[\ldots]$ the supervisors in the process and not really much the students feel they can do.

Or as Gerald, a social science candidate aptly put it: 'You don't want a reputation as someone who creates trouble'.

Many candidates on this sample reported on their exercise of what might be best described as a cautious diplomacy towards what they put in writing; and attempted to reduce their 'visibility' in the system. Bert highlights the powerlessness of candidates in this equation:

[I]t's very difficult for any group, regardless of how anonymously they want to handle it, to approach your supervisor to talk about the issues of problems with their conduct as a supervisor because they're going to know, and they would be able to work out from a very small list of people, who might have raised it.

Although it seemed that most students were merely wary of the potential for supervisors to abuse a position of power, some students internalised the power relations inherent in candidature. These candidates not only reported their reluctance to pass critical comment on their supervisors, but questioned their qualifications to make such an assessment. Ylva's comments vividly express this: '[Y]ou don't want to ruin a reputation. Who am I? A novice: a novice apprentice researcher'. 


\section{Conclusion}

The findings of our research have consequences for assessing the effectiveness of the administration of research students, and unsettle the assumption that audit cultures are necessarily transparent and efficient. Our findings call into question the usefulness of the annual or bi-annual progress report as currently utilised in many Australian universities. These findings may be generalisable beyond the Australian higher education system to universities in other countries which rely on similar progress reporting processes - such as Europe (EUA, 2010). As a result of this research, we argue that progress reporting needs to be re-oriented from its role within the administrative apparatus of graduate research management and embedded in the pedagogy and curriculum of research training.

Our study also uncovers problematic variations in what research candidates and their supervisors actually think about the purposes of the progress reporting process. While some candidates and supervisors use the progress report for planning and self-reflection, they overwhelmingly express a strong institutional understanding of the progress report as being merely an administrative exercise lacking pedagogical value. Further, multiple reporting lines can mean candidates and supervisors get drawn into excessive reporting that ceases to be useful for the successful conduct of candidature.

Our research calls into question the effectiveness of managerial cultures on processes of formative assessment and student learning. While we found that social learning was used by students and their supervisors to learn how to manage themselves within an accountability landscape; this learning consisted largely of the ability to make multiple performances of 'research competency', both in person and on paper. Saying the unsayable - or finding ways to 'speak back to power' were problematic for supervisors and candidates alike. If, as our data reveals, students found themselves unable or unwilling to comment on their supervisors' performance, this incapacity to speak also affects supervisors, who struggle with the reporting of unsatisfactory progress of candidates. Silences and self-censoring produce documents whose authors' effectively collude at obfuscation (Cuthbert and Spencer 2001).

One finding stands out above all others: progress reports are not always what the institution presume they should be: an accurate account of the progress and problems developing during candidature. This finding highlights the problematic tendency for audit cultures to generate another form or another process to address intransigent problems: a tendency, Baird (2010) identifies as the 'more is always better' approach. Although accountability is supposed to produce transparency, those who manage accountability can be 'frequently unclear over their multiple expectations and thus generate more noise and confusion'. Our data provides evidence to support Baird's assertion that when there are 'too many demands from too many people' the ability for actors to actually make themselves accountable is compromised (Baird 2010, 132). It also reinforces critics such as Sparkes (2007) and Gill (2009) who call attention to the human costs of such institutional measuring practices. They question the reason for the existence of such forms and paperwork if they do not achieve the very purpose they are designed for.

In concluding that progress reports are not always truthful or accurate accounts of progress, it is important to emphasise that it does not then follow that blame for the untruths or inaccuracies needs to be apportioned to one or other parties to the report. The tensions and conflicting demands produced by these multiple and sometimes conflicting relationships described by our participants gives us a rich background against which to understand some of the issues highlighted in this study. Our participants revealed that most parties thought they were negotiating in good faith to produce good outcomes, which sometimes involved bending, or ignoring official rules and working to local and specific circumstances. Often this worked, but there is always the potential for unexpected consequences down the track, especially in cases in which the candidature goes off the rails.

In the research degree management landscape accountability relationships are more than institutional - they are also personal, financial and disciplinary. Clarity is needed regarding to 
whom students, supervisors and the institution are being accountable in their reporting practices; and the accountability owed to the authors of reports in which problems and impediments to progress are identified. One way to achieve this is to look for what Cuthbert describes as 'cultural remedies' (2004). Cuthbert outlined strategies aimed at shifting reporting from a 'bureaucratic imposition' to ones that encourage all parties to see progress reporting as an opportunity to report barriers and impediments to progress so that action to address these might be taken.

At the institution in which this study was conducted, the progress reporting process was squarely located in the administrative apparatus of candidature management. The findings from this research highlight the disjunctures that exist between well-intentioned policy and the understandings and practices which circulate around this which may subvert the intended purpose and produce other unintended outcomes. Our data points to the need for the process of reporting on the progress of research to be re-positioned and re-oriented from its current position within the administration of research education to a more meaningful location - for candidates and their supervisors - within the pedagogy and curriculum of higher degree by research delivery. Such re-positioning may encourage greater openness and transparency about progress in research than exists in the current practice, and build educationally meaningful conduits of reporting, formative review and accountability across the congested terrain of higher degree by research candidature.

\section{References}

Australian Business Foundation. (1997). The high road or the low road: alternatives for Australia's future. Sydney: Australian Business Foundation.

Baird, J. (2010). Accountability relationships in Australian Postgraduate research education. Quality in postgraduate research conference: educating researchers for the 21st century, Adelaide, Australia.

Becher, T., \& P. Trowler. (2001). Academic tribes and territories: Intellectual enquiry and the culture of disciplines (2nd ed.). Buckingham: The Society for Research into Higher Education \& Open University Press.

Cotterall, S. (2011). Doctoral students writing: where's the pedagogy? Teaching in Higher Education, 16(4), 413-425.

Crossouard, B. (2008) Developing alternative models of doctoral supervision with online formative assessment, Studies in Continuing Education, 30(1), 51-67.

Cumming, J. (2009). The doctoral experience in science: challenging the current orthodoxy, British Educational Research Journal, 5(6), 877-890.

Cuthbert, D., \& C. Spencer. (2001). White lies, damned lies and annual progress reports of HDR candidates and their supervisors. Australian Association of Institutional Researchers (AAIR) Forum 2001: Proceedings: University of Central Queensland. Retrieved December 5th, 2011 from http://www.aair.org.au/jir/html/Papers2001.htm

Cuthbert, D. (2004). Quality assurance in research training: A view from the humanities and social sciences, Proceedings of the Australian Universities Quality Forum.

Department of Innovation, Industry, Science and Research (DIISR). (2011). Defining Quality for research training in Australia, Melbourne: Department of Innovation, Industry, Science and Research.

Department of Education, Training and Youth Affairs (DETYA). (2001). Factors associated with the completion of research higher degrees, Report No. 37, Sydney: Department of Education, Training and Youth Affairs.

European University Association. (2010). ARDE Focus group1. Indicators and data collection: Monitoring the doctoral cycle. Retrieved June $18^{\text {th }}$, 2012, from http://www.eua.be/euaprojects/current-projects/accountable-research-environments-for-doctoral-edu.aspx.

Excellence in Research Australia. (2011). Retrieved December 5th, 2011 from http://www.arc.gov.au/era/era_2010/era_2010.htm 
Gill, R. (2009). Breaking the silence: The hidden injuries of neo-liberal academia. In, R. Flood \& R. Gill, (Eds.), Secrecy and silence in the research process: Feminist reflections. London: Routledge.

Golde, C. (2005). The role of the department and discipline in doctoral student attrition: lessons from four departments. The Journal of Higher Education, 76(6), 669-700.

Halse, C. \& Mowbray, S. (2011). The impact of the doctorate. Studies in Higher Education, 36(5), 513-525.

Holbrook, A, Bourke, S., Lovat, T. \& K. Dally, K. (2004). Qualities and characteristics in the written reports of doctoral thesis examiners. Australian Journal of Educational \& Developmental Psychology, 4, 26-145.

Kelly, F. (2009). Supervision: satirized fictional narratives of student-supervisor relationship. Arts and Humanities in Higher Education, 8(3), 368-384.

Kehm, B. M. \& Teichler, U. (2007). Research on internationalisation in higher education. Journal of Studies in International Education, 11, 260-273.

Kiley, M \& Wisker, G. (2009). Threshold concepts in research education and evidence of threshold crossing. Higher Education Research and Development, 28(4), 431-441.

Lave, J. \&, E. (1991). Situated learning: Legitimate peripheral participation. Cambridge: Cambridge University Press.

Lee, A., Johnson, L. \& Green, B. (2000). The PhD and the Autonomous Self: Gender, rationality and postgraduate pedagogy. Studies in Higher Education, 25(2), 135-147.

Lee, A. \& Williams, C. (1999). Forged in fire: narratives of trauma in PhD supervision pedagogy. Southern Review, 32, 6-26.

Lovitts, B. E. (2001). Leaving the ivory tower: The causes and consequences of departure from doctoral study (1st ed.). New York: Rowman and Littlefield Publishers, Inc.

Lucas, L. (2006). The research game in academic life. Open University press.

Marginson S., \& Considine, M. (2000). The enterprise university: Power, governance and reinvention in Australia. Cambridge UK: Cambridge University Press.

Morgan, D. L. (1997). Focus groups as qualitative research. London: Sage.

Martinsuo, M. \& Turkulainen, V. (2011). Personal commitment, support and progress in doctoral studies. Studies in Higher Education, 36(1) 103-120.

Organisation for Economic Co-operation and Development (OECD) (1996). The knowledge-based economy. Paris: Organisation for Economic Co-operation and Development.

Petersen, E. (2007). Negotiating academicity: postgraduate research supervision as category boundary work. Studies in Higher Education, 32(4), 475-487.

Sparkes, A. (2007). Embodiment, academics, and the audit culture: a story seeking consideration, Qualitative Research, 7, 521-530.

Strathern, M. (ed.). (2000). Audit cultures: anthropological studies in accountability, ethics and the academy. London: Routledge.

Strauss, A., \& J. Corbin. (1998). Basics of qualitative research. Thousand Oaks: Sage.

Thornton, M. (2009). Academic Un-freedom and the new knowledge economy. In A. Brew \& L. Lucus (Eds), Academic research and researchers. Maidenhead: Open University Press.

Tinkler, P \& Jackson, C. (2010). Back to Basics: a consideration of the purposes of the PhD viva. Assessment \& Evaluation in Higher Education, 26(4), 355-366.

United Kingdom Department of Trade and Industry (DTI). (1998). Our competitive future: building the knowledge driven economy. London: Department of Trade and Industry.

UNESCO (2004) Doctoral Studies and Qualifications in Europe and the United States: Status and Prospects, Sadler, J. (Ed). Bucharest.

Word count 6836 